\title{
PROJETOS DE VIDA DE ADOLESCENTES E JOVENS DE COMUNIDADES QUILOMBOLAS DO VALE DO MUCURI/MG*
}

Eva Aparecida da Silva**

Resumo: Este artigo traz informações sobre a pesquisa "Projetos de vida de jovens quilombolas", financiada pela Fapemig, no período de 2012 a 2014, realizada com adolescentes e jovens das comunidades remanescentes de quilombo Cama Alta, Córrego Novo e São Julião, situadas no município de Teófilo Otoni, pertencente à mesorregião do Vale do Mucuri, Minas Gerais. Nesse estudo pudemos apreender, por meio de três instrumentos de coleta de dados (questionário, entrevista e roda de conversa) a educação enquanto o principal componente na construção dos projetos de vida desses sujeitos adolescentes-jovens. Eles atribuem a ela papel importante na conquista de uma profissão que venha a possibilitar melhores condições de vida para sua família (a dos pais ou parentes mais próximos e aquela que poderão constituir). Muitos deles desejam se tornar professores, veterinários, engenheiros e, para isso, consideram que devem se dedicar aos estudos. O apoio da família também se mostra imprescindível para a efetivação desse desejo. Embora desejem algumas das profissões que conferem status social, especialmente nos grandes centros urbanos, alguns jovens não veem como alcançá-las e, por isso, visualizam atividades que os mantenham no rural, mas com certos privilégios, tais como vaqueiro e fazendeiro. Muitos deles expressam a vontade de, por meio dos estudos e do exercício da profissão escolhida, viver fora da comunidade. Se, por um lado, a educação escolar é tida pelos jovens como meio de obter melhores condições de vida, com o exercício de uma profissão e de saída da comunidade, por outro lado, ela também se mostra um obstáculo à concretização de seus projetos de vida. Essa contradição é percebida na descrição acerca da falta de estrutura das escolas frequentadas, física e de recursos humanos. Eles não têm clareza acerca da possibilidade de uma educação escolar quilombola (Parecer CNE/CEB 16/2012) que articule saberes tidos como universais e saberes que dão ênfase à identidade étnico-racial, à história e cultura da África e afro-brasileira (Lei 10639/2003) e às questões que envolvem território e territorialidade, próprios à condição de negro, rural e quilombola, mas a percepção acerca do descompasso entre o conhecimento escolar e aquele que emerge das experiências cotidianas dessas comunidades.

Palavras-chave: Comunidades remanescentes de quilombo. Projetos de vida. Adolescentes e jovens.

\footnotetext{
* Este artigo resulta da pesquisa "Jovens quilombolas e seus projetos de vida", realizada no período de 2012 a 2014 , com financiamento da FAPEMIG. Aderiram ao projeto sessenta sujeitos adolescentes e jovens, distribuídos por comunidade da seguinte forma: vinte e três da Córrego Novo, dezessete da Cama Alta e vinte da São Julião. A coleta de dados foi feita por meio de três instrumentos: questionário socioeconômico e cultural, para traçar o perfil dos jovens e adolescentes investigados, entrevista individual semiestruturada e reuniões de grupo, empregando a técnica de Roda de Conversa. Esta pesquisa foi coordenada pela autora deste artigo e também contou com a participação da professora/pesquisadora Niusarte Virgínia Pinheiro (UFVJM) e das então alunas/pesquisadoras Adriana Pereira de Lima (Curso de Serviço Social/UFVJM; bolsista IC), Sidimara Cristina de Souza (Curso de Serviço Social/UFVJM, bolsista IC) e Bárbara Figueiredo Ruas Dias (Curso de Matemática/UFVJM, bolsista IC).

** Graduada em Ciências Sociais (UNESP), mestre e doutora em Educação - Área Ciências Sociais Aplicadas à Educação (FE/ UNICAMP), professora adjunta da Universidade Federal dos Vales do Jequitinhonha e Mucuri (UFVJM), no período de 2007 a 2014, professora assistente doutora da UNESP, Campus de Araraquara, a partir de 2014. e-mail: evasilva@fclar.unesp.br.
} 


\begin{abstract}
This article provides information about the research "quilombo young life projects" financed by Fapemig in the period 2012-2014, carried out with young people of quilombola communities Cama Alta, Córrego Novo and São Julião, located in the municipality of Teofilo Otoni, belonging to the middle region of the Mucuri Valley, Minas Gerais, Brazil. We apprehended through three data collection instruments (questionnaire, interview and conversation wheel) education as the main component in the construction of such subjects' life projects. They attribute its important role in the achievement of a profession that will enable better living conditions for their families (the parents or close relatives and one that may be). Many of them wish to become teachers, veterinarians, engineers, and, therefore, consider that much time must be devoted to their studies. Family support also proves indispensable for the realization of this desire. While wishing some of the professions that confer social status, especially in large urban centers, some young people do not see how to achieve them, and therefore visualize activities that keep them in the country, but with certain privileges, such as to be cowboys and farmers. Many of them express the will, through the study and practice of chosen profession, to live outside the community. If on one hand school education is seen by young people as a means of better living conditions, through the exercise of a profession, and community output, on the other hand, it also shows an obstacle to the realization of their life projects. This contradiction is seen in the description about the lack of structure of schools attended, physical and human resources. They do not have clarity about the possibility of a quilombo education (CNE / CEB 16/2012) that articulates knowledge regarded as universal and knowledge that focus on ethnic-racial identity, history and culture of African and Afro-Brazilian (Law 10639/2003) and the issues surrounding territory and territoriality, peculiar to the condition of black, rural and quilombo groups, but the perception of the mismatch between school knowledge and the one that emerges from the everyday experiences of these communities.
\end{abstract}

Key Words: Quilombola communities. Life projects. Teens and young people. 
92 SILVA. Projetos de vida de adolescentes e jovens de comunidades quilombolas do Vale do Mucuri

história comum, construída com base em vivências e valores compartilhados (ARRUTI, 2003).

Este artigo coloca em evidência os projetos de vida de adolescentes e jovens de comunidades remanescentes de quilombo do Vale do Mucuri/MG (Cama Alta, Córrego Novo e São Julião), com base na apreensão de quem são esses sujeitos, em que condições vivem, o que pensam, sentem e como agem frente a suas dimensões sociais, econômicas, culturais e educacionais.

O Vale do Mucuri, mesorregião do Estado de Minas Gerais, é composto por dezenove comunidades pré-identificadas remanescentes de quilombo, de acordo com o estudo realizado pelo Centro de Estudos Eloy Ferreira da Silva (CEDEFES), no período de 2003 a 2007. Entre os municípios do Mucuri, nos quais estão localizadas comunidades quilombolas, Teófilo Otoni abriga cinco delas: quatro rurais (Cama Alta, Imburama, São Julião e Fazenda Pedra Azul) e uma urbana (Palmeiras ou Marquem da Linha (CEDEFES, 2008).

No entanto, em pesquisa realizada por Silva et alii (2010), constatou-se que os Imburamas representam um dos quatro (4) núcleos familiares que compõem a comunidade quilombola Córrego Novo, situada no distrito de Topázio, e a Pedra Azul é um dos pequenos núcleos de povoamento, denominado Sítio Pedra Azul, pertencente à comunidade Marques I, localizada no município de Carlos Chagas. Logo, o município de Teófilo Otoni possui três comunidades rurais negras (Cama Alta, Córrego Novo e São Julião) e um "quilombo urbano" (Palmeiras ou Margem da Linha).

Essas comunidades desviam-se do modelo tradicional de quilombo - "reduto de escravos fugitivos" (RATTS, 2006) - e se aproximam da ideia contemporânea de grupo étnico, coletivos que se estabeleceram em terras ocupadas e nelas reproduzem seus modos de vida característicos, tomando como referência uma

A formação de comunidades quilombolas em Minas Gerais aconteceu após a abolição da escravidão. Muitas famílias negras migraram para grotões, terras desabitadas ou margens de fazendas, poucas receberam terras doadas de seus antigos senhores ou compraram pequenas terras nas fazendas onde trabalhavam e se fixaram em áreas rurais de difícil acesso (CEDEFES, 2008).

Para Silva (2010), tomando como referência Ribeiro (s/d.), a formação de remanescentes de quilombo no Vale do Mucuri tem início no final do século XIX com o movimento migratório e povoador do alto Jequitinhonha para o baixo Jequitinhonha e Mucuri. Nesse momento intensifica-se o processo de posse ou compra de terras, que poucas vezes envolvia dinheiro, mas trocas por mantimentos e bens diversos.

Os principais motivos que levaram a essa migração são o esgotamento das lavras de ouro e diamante e das lavouras, bem como as duas grandes secas ocorridas nos anos 1890 e 1930. Em sua maioria, migravam "os jovens e os libertos do cativeiro procurando terras sem donos, levando consigo apenas machado, isqueiro, coragem e necessidade" (RIBEIRO, $\mathrm{s} / \mathrm{n}, \mathrm{p} .19)$.

No caso de São Julião e Cama Alta, a apropriação inicial da terra se deu por posse e no de Córrego Novo, por compra, embora não haja documento que ateste essa transação. Nelas, o processo de construção da identidade remanescente de quilombo ocorre num tempo e espaço próprios.

Cama Alta fica a $45 \mathrm{~km}$ do município de Teófilo Otoni, exatamente em um de seus distritos - Brejão. De acordo com o relato dos mais velhos, o primeiro a chegar no lugar, no início do século XX, foi o "velho capixaba", que "comprou o pedaço de terra nas mãos de outro", sem, contudo, se valer de um documento de compra e propriedade da terra. Em seguida, por 
93 SILVA. Projetos de vida de adolescentes e jovens de comunidades quilombolas do Vale do Mucuri volta do ano de 1915, vieram outros da região de Salinas (Norte de Minas Gerais), "fugidos da seca", adentraram na mata, "abriram posse" e construíram sua casa. Os moradores contam que o nome dado à comunidade se deve à expressiva presença de onças no que era o "roçado" daquela época, o que fazia com que as "camas" se encontrassem no alto. Essa comunidade conta com 113 habitantes e trinta e cinco famílias.

São Julião, também conhecida como Lavra dos Pretos, devido à concentração de minérios na região, está situada a $83 \mathrm{~km}$ de Teófilo Otoni, próxima ao distrito de Maravilha. Segundo a matriarca da comunidade, os primeiros moradores vieram de um lugarejo próximo à cidade de Jequitinhonha - ao que tudo indica Felisburgo. Essa cidade não seria, entretanto, o local de origem desse processo migratório, mas, sim, alguma outra do Estado da Bahia. A formação da São Julião também está ligada à fuga das famílias da Guerra do Paraguai (1864-1870), pois se acreditava que os jovens seriam recrutados para compor a frente de batalha, e à busca por melhores condições de vida e de um lugar para fixar residência. Os descendentes dos fundadores somam-se a outros núcleos familiares e muitos deles têm uma relação de parentesco uns com os outros, fazendo de São Julião uma grande parentela. A comunidade possui 259 habitantes e sessenta e duas famílias.

Córrego Novo está a $40 \mathrm{~km}$ de Teófilo Otoni, no distrito de Topázio, pertencente ao município de Teófilo Otoni. Segundo um dos membros mais velhos da comunidade, seus pais chegaram à região do Vale do Mucuri onde hoje está Córrego Novo por volta de 1929 e já encontraram ali instalado "Manezinho da Cachoeira", de quem compraram a terra, e os Imburamas, que "abriram posse" na mata ainda pouco povoada. De suas lembranças sobre a infância, ele destaca as experiências vividas com situações extremas, como as noites de frio em que dormia próximo a uma pequena fogueira feita no interior da casa e acordava com as pernas chamuscadas pela brasa (os sinais que ainda avivam essas memórias podem ser vistos

nas cicatrizes que ficaram em suas pernas); a pouca roupa que podia cobrir seu corpo, uma espécie de "tanguinha", feita de tecido tipo saco e as refeições, pouco variadas, cujo prato principal era quase sempre o "coió", tubérculo que deveria ser cozido no sal para tirar o efeito de uma substância que parecia cortar a língua até sangrar. A comunidade é composta por quatro núcleos familiares, 173 habitantes e quarenta e seis famílias.

Hoje São Julião é certificada pela Fundação Cultural Palmares, tem uma associação quilombola e busca a titulação de suas terras junto ao INCRA. Cama Alta dá os primeiros passos rumo à certificação e à constituição da associação e Córrego Novo ainda articula timidamente terra e território a uma "identidade quilombola", de modo a mobilizar elementos que remetam a uma cultura e história específicas, compartilhadas pelo grupo.

AdOlescentes E JOVEnS QUILOMbOLAS, PERCEPÇÕES E PROJETOS DE VIDA

Ao viver a juventude ou juventudes em suas múltiplas dimensões, como defende Dayrell (2007), os jovens, inseridos em espaços e tempos específicos, repletos de descobertas, ambivalências, emoções e conflitos, se defrontam com as seguintes questões: "Quem sou eu? Para onde vou? Qual rumo devo dar a minha vida?" Essas e outras indagações remetem a seus projetos de vida.

[...] uma ação do individuo de escolher um, entre os futuros possíveis, transformando os desejos e as fantasias que lhe dão substância em objetivos passiveis de serem perseguidos, representando, assim, uma orientação, um rumo de vida. Nesse sentido, o projeto não deve ser entendido como resultado de um cálculo matemático, estrategicamente elaborado, ou de um processo linear, como 
está presente no senso comum. A ideia de projeto de vida remete a um plano de ação que um indivíduo se propõe a realizar em relação a alguma esfera de sua vida (profissional, escolar, afetivo etc.) em um arco temporal mais ou menos largo. Tais elaborações dependem sempre de um campo de possibilidades dado pelo contexto socioeconômico e cultural no qual cada jovem se encontra inserido e que circunscreve suas experiências Nesse sentido, o projeto possui uma dinâmica própria, transformando-se na medida do amadurecimento dos próprios jovens e/ou mudanças no seu campo de possibilidades. Eles nascem e ganham consistência em relação às situações presentes, mas implicando, de alguma forma, uma relação com o passado e o futuro. Nesta formulação, falar em projeto é referir-se a uma determinada relação com o tempo, em especial o futuro, e especificamente às formas como a juventude lida com esta dimensão da realidade (LEAL; DAYRELL; REIS, 2011, p. 1071-2).

\section{É nessa perspectiva que entramos em contato} com os projetos de vida dos adolescentes e jovens das comunidades remanescentes de quilombo Córrego Novo, Cama Alta e São Julião, sujeitos negros, quilombolas e rurais, inseridos em espaços e tempos específicos a essas múltiplas identidades e com base nos quais refletem acerca dos seus projetos, quais são seus limites e suas possibilidades.

Esses projetos puderam ser apreendidos em algumas de suas dimensões por meio dos questionários aplicados para traçar seu perfil socioeconômico e cultural, os quais sinalizam para as expectativas de cursar o ensino superior ou técnico e, com isso, trabalhar em profissões de qualquer área que lhes assegurem melhores condições de vida; das entrevistas relacionadas aos seus interesses profissionais, vida escolar, social e familiar, auto avaliação e expectativas futuras e, por fim, das rodas de conversa acerca da identidade, autoestima, ser adolescente/jovem, interferência da família e da escola na construção do projeto de vida, protagonismo juvenil, políticas públicas para a adolescência/juventude e projeto de vida.

No contato com suas auto avaliações, as quais envolvem a identidade (adolescente, jovem, rural, negra ou não negra, quilombola, feminina, masculina) e a autoestima, observa-se que a maioria se diz satisfeita com a vida que tem e consigo mesma.

Entre as qualidades destacadas por eles estão: simpático(a), curioso(a), inteligente, bonito(a), educado(a), feliz, estudioso(a), irresistível, "boa gente", "cara bacana", tranquilo(a), nem bonito(a) nem feio(a), mais ou menos bonito(a), "descolada" ("conversa com todo mundo"), "de atitude", "pessoa muito amiga", meiga, gentil, "ajuda pessoas", honesto(a), "brincalhão", trabalhador, responsável, "alegre com as pessoas", sincera, "respeitadora", paciente. Há aqueles que se julgam mais ou menos inteligentes ou, ainda, não inteligentes. Pelo observado, esse julgamento está diretamente relacionado ao desempenho nas diferentes disciplinas oferecidas pela escola, nas respectivas séries/anos cursadas por eles.

A escola e seu modelo tradicional de avaliação têm grande responsabilidade na baixa-estima de muitos de seus alunos, uma vez que associa uma nota ou um conceito, atribuído ao final do processo de aprendizagem, ao ser ou não portador de inteligência.

Concomitante às qualidades, eles também destacam os defeitos: teimosa, tímido(a), "exibido demais", "fala demais", "chata", "mal humorada", "não gosta de compartilhar o lanche", "usar roupa curta", "boca dura" (responde imediatamente aos xingamentos), "meio nervoso", "sorrir dos outros", "um pouco egoísta", "conversar sozinho", "não dá importância para o que os outros falam", "incomodar com a vida dos outros", "ser baixa", "as pessoas dizem que conto muitas mentiras", "não gostar de brincadeiras", "ser realista".

No entanto, em meio às declarações de satisfação com a vida, geralmente em virtude de ser feliz, de estar próximo à família, de ter liberdade, de ter o 
95 SILVA. Projetos de vida de adolescentes e jovens de comunidades quilombolas do Vale do Mucuri que quer e poder viver num lugar (a comunidade) em que impera a união entre seus integrantes, bem como com a aparência física, alguns adolescentes e jovens manifestam insatisfação por ambos (a vida e o corpo).

No que se refere à vida, as insatisfações estão diretamente relacionadas com as dificuldades vividas pelas comunidades (falta de infraestrutura, moradia, transporte etc.) e com as dificuldades financeiras de cada família.

...um pouco satisfeito com a vida na comunidade... às vezes fico satisfeito com umas coisas, outras não...aqui as coisas é muito difícil. (Jovem da comunidade São Julião)

...a gente não se sente feliz quando ele [padrasto] tá com um emprego ruim, né, que tá com muitas dívidas. (Adolescente da comunidade Córrego Novo)

Quando elas se referem ao corpo, adolescentes e jovens desejam ser mais baixas ou mais altas, terem menos barriga, não serem gordos(as), terem corpo, olhos azuis, não terem espinhas no rosto, "terem mais atitude para conversar", "não terem pés pequenos e achatados", não terem marcas no corpo, resultado de uma surra que levou "de um dos pais de suas irmãs" e, principalmente, terem outro tipo de cabelo, aquele que não seja "meio crespo" ou "ruim".

Tem alguma coisa que você mudaria em você?

Não, só o cabelo mesmo (rsrsrsrs...), é meio crespo, mas dá pra levar. (Jovem da comunidade São Julião)

O que você mudaria, pra ficar mais bonitinha?

O cabelo só, por que se crescer mais um pouquinho muda a aparência. (Jovem da Córrego Novo)
... queria mudar o cabelo...nossa, ele é feio pra caramba!... feio demais, ainda mais pra pentear (Adolescente da comunidade Córrego Novo)

Gostaria que o cabelo fosse diferente, pois diz que ele é ruim (Adolescente da Cama Alta).

Como demonstrou Gomes (s.d.), corpo, em particular a cor da pele, e cabelo são dois importantes ícones no processo de construção da identidade negra. O cabelo, sobretudo, define a maneira como o negro se vê e é visto pelo outro, atuando em alguns casos em sua valorização e em outras situações continua sendo tomado como uma marca de inferioridade, não associada à beleza. Na sociedade brasileira, ...o cabelo do negro, visto como "ruim",
é expressão do racismo e da desigual-
dade racial que recai sobre esse sujeito.
Ver o cabelo do negro como "ruim" e
do branco como "bom" expressa um
conflito. Por isso, mudar o cabelo pode
significar a tentativa do negro de sair
do lugar de inferioridade ou a introje-
ção deste. Pode ainda representar um
sentimento de autonomia, expresso nas
formas ousadas e criativas de usar o ca-
belo. (GOMES, s.d., p. 3).

Pelo observado, constata-se que o desejo de adolescentes e jovens quilombolas em mudar ou não ter o cabelo crespo decorre das experiências com sua depreciação, vividas tanto nas relações com os de fora da comunidade quanto com os "iguais" (de dentro da comunidade), todas elas permeadas pelo racismo, introjetado como verdade, até mesmo pelos próprios negros. Entretanto, há aqueles que dizem gostar do cabelo, por ser ele representativo de sua identidade negra, como relatou uma jovem da comunidade São Julião, ao viver uma experiência como integrante de 
96 SILVA. Projetos de vida de adolescentes e jovens de comunidades quilombolas do Vale do Mucuri uma fanfarra e ter que alisar o cabelo para se "tornar igual" às outras meninas.

A vestimenta igual, a roupa, o que calça, como faz o cabelo, e aí tinha que fazer uma trança no cabelo, aí meu cabelo não dava, é muito cacheado, aí não fica a trança, e não fica grande, e todos os cabelos das outras eram maiores, ou liso alguma coisa assim, loiro, que dava pra fazer a trança, ai eu tive que alisar o cabelo pra fazer a trança. Foi quase obrigado, porque eu não queria fazer isso, mas eu queria entrar na fanfarra, quem tá de dentro não pode sair mais, então, como eu tava dentro, eu tive que fazer isso pra conseguir fazer a trança. Assim, não foram eles que obrigaram, mas a situação obrigou a fazer, então é quase um racismo.

E há aqueles que gostam do cabelo pelo fato de, ao contrário, ser mais liso e comprido, portanto, próximo ao cabelo "bom". Alguns sujeitos também disseram gostar de seus dedos, dos braços, da boca, do sorriso e dos olhos cor de mel (nem verde, nem azul).

Questionados sobre a existência do racismo e sobre experiências vividas ou observadas com ele, os jovens da comunidade São Julião reconhecem que ele existe, mas não julgam vivê-lo, com exceção daqueles que o percebem sutilmente em "brincadeiras", em apelidos, como negão, mais no universo externo, principalmente na escola, do que no interior da própria comunidade. No entanto, as chamadas "brincadeiras" escondem o verdadeiro sentido do racismo. Elas também são vividas e/ou observadas pelos jovens da Cama Alta, os quais demonstram maior percepção de seu sentido.

Sendo a escola um dos principais espaços de sua atuação, não há trabalhos significativos de combate ao racismo, de reeducação de posturas racistas, mas apenas referência ao processo de colonização e escravidão vivido pelo Brasil, especialmente na disciplina de História e em atividades pontuais no dia 20 de novembro (Dia da Consciência Negra), como, por exemplo, capoeira e palestras. Os jovens da São Julião relataram ter tido contato com uma pessoa que foi para um dos países africanos de religião mulçumana e com alguns traços culturais desse país. Os de Cama Alta destacaram o concurso da beleza negra, ocorrido em 20 de novembro e o debate acerca de um texto sobre Martin Luther King, na disciplina de Português.

Quando o assunto diz respeito aos interesses profissionais, adolescentes e jovens, homens e mulheres, destacam várias profissões ou ocupações visualizadas como possíveis alocações futuras, algumas de mais fácil acesso do que outras. Entre elas estão: veterinária, pedreiro, ginasta, advogada, cantor(a), promotora de eventos, engenheira(o), arquiteta(o), professor(a); nesse caso, alguns especificam a área da docência, em especial Matemática e Português, jogador de futebol, bombeiro, policial, delegada, modelo, operador de telemarketing, médica ou paleontóloga, atriz, cozinheiro, enfermeira, vaqueiro, "trabalhar na roça”, peão de rodeio. Há aqueles que dizem não saber ou não ter pensado ainda sobre uma profissão.

$\mathrm{O}$ interesse pelas profissões ligadas à área da saúde, como médico(a) e enfermeira(o) ocorre pelo fato de vivenciarem a dificuldade no acesso a esse serviço e a importância que ele assume no cuidar de pessoas que necessitam de ajuda, seja nas próprias comunidades, seja numa realidade mais ampla, a brasileira. Uma adolescente da comunidade Córrego Novo e uma jovem da Cama Alta relatam:

[...] é porque toda vez que eu vou no posto eu vejo muita gente na fila esperando, demora muito, assim;

A profissão dos sonhos é a medicina. "Mas só que ai é um processo muito difícil para mim, porque medicina precisa de muito estudo, sabe; como eu estudo em uma escola pública, pra mim eu acho que seria muito difícil ter acesso a uma universidade, um curso mais apropriado para isso, e então eu tô querendo mesmo é começar do baixo, sabe, primeiro eu vou começar a trabalhar e, como eu ainda sou jovem, a partir do que a gente for ficando mais velho, sabe, 

agente vaii mudando as opiniões. O que levou a escolher essa profissão foi ver muitas pessoas através da radio e televisão sofrerem por causa da precariedade da saúde, e poder ajudar as pessoas que necessitam.

meio a esses desejos e incertezas, por não visualizar ter condições (materiais, principalmente) para se definir por uma delas, expressa sonhar ser peão de rodeio, uma atividade que parece mantê-lo em contato com o universo rural, ainda visto como possibilidade, apesar das adversidades.

A adolescente da comunidade Córrego Novo ainda deseja ser paleontóloga, aquela que “...estuda os animais que já morreram”, e diz também gostar muito de "cuidar de criança pequena". Entre os seus gostos e desejos, percebe-se que o "cuidar de criança pequena" é destacado por ela como o possível para o momento e ser médica ou paleontóloga, uma projeção para o futuro.

A escolha pela veterinária, por outro lado, feita por alguns adolescentes e jovens, está relacionada ao gosto por animais e aos cuidados com eles, decorrente do que é a vida no mundo rural, já que se trata de sujeitos pertencentes às comunidades rurais negras (ou comunidades remanescentes de quilombo) e devido ao contato com alguns desses profissionais.

[....] é bom a gente mexer com criação... já vi eles [veterinários] trabalhando nas fazendas...vi eles cuidando, aí a gente interessa também (adolescente da comunidade Córrego Novo)

$\mathrm{O}$ viver no mundo rural também faz que um ou outro não queira sair da comunidade na qual nasceu e cresceu, apenas em último caso, e, por isso, expressam o interesse em continuar trabalhando na roça, uma vez que essa experiência já é vivida por eles.

Trabalhar na roça, porque meus pais ficam aqui, mas se não der pra trabalhar aqui, vou sair (jovem da comunidade São Julião).

Um dos adolescentes da comunidade Córrego Novo, que atualmente exerce a atividade de vaqueiro, por meio período do dia, aponta para algumas profissões desejadas, como bombeiro, policial e engenheiro, embora ouça que "isto é para rico". Em A infuência da família também está presente entre aqueles que querem ser cantores, como é o caso de duas jovens da comunidade São Julião, embora uma delas apenas ocasionalmente, pois quer ser professora. Ambas têm referência na família Pereira, fundadora da São Julião, seja na matriarca dessa comunidade, seja num dos filhos dessa família, cantor e violeiro de expressão regional e nacional.

...dizem que eu canto bem (rsrs...) a é, comecei na escola, tinha gincana, assim no meio do ano tem gincana, né, aí tem várias brincadeiras, que a gente faz, ai tinha show de calouros (rsrs) ai eu entrei uma vez e gostei, sabe, tudo mundo torceu e disse que eu me dava bem nisso... meus amigos sempre falam: Quando você terminar, os estudos... Você poderia fazer um curso de música (jovem da comunidade São Julião). 

efetivo.

Um adolescente da comunidade Córrego Novo quer ser operador de telemarketing, pois seu irmão trabalha nessa atividade em Belo Horizonte, desde que migrou, o que sinaliza também seu desejo de ir embora da comunidade. E outro, cozinheiro, também por influência da irmã e de sua madrinha.

Por outro lado, uma das jovens da comunidade São Julião visualiza se tornar promotora de eventos, pois gosta "de organizar coisas, tipo assim na escola, que tem em frente a minha casa...pelo gosto de ver as pessoas organizando as coisas".

Ao mencionarem seus interesses profissionais, notamos que adolescentes e jovens das três comunidades remanescentes de quilombo de Teófilo Otoni/ MG atribuem à educação escolar um papel crucial na concretização de seus projetos de vida. Alguns enfatizam o gosto pelos estudos, no momento em que vivem o processo de escolarização e, ao viverem, o veem como meio para atingir a profissão desejada; outros, por outro lado, sabem de sua importância mesmo reconhecendo não gostar de estudar.

A falta de gosto pelos estudos, na maioria das vezes, está associada às dificuldades para aprender, em especial o Português e/ou a Matemática, mas também às frustrações com a própria escola. Quando relatam sobre as potencialidades da educação escolar na consecução de seus projetos de vida, alguns sujeitos também apontam seus limites, como é o caso das más condições físicas em que se encontra a escola e, sobretudo, da constante ausência de professores, pois eles chegam a ficar meses sem aulas de História, Português ou Matemática.

Menção também é feita à importância da família, em especial ao que é a figura dos pais, ou de um deles, na concretização de seus projetos de vida, sobretudo no que diz respeito ao incentivo que ela pode dar nesta trajetória repleta de desejos, certezas e incertezas, já que o apoio financeiro não se torna
No entanto, apesar de todas as adversidades, suas expectativas para o futuro são animadoras, uma vez que boa parte acredita ser possível estudar, "arrumar um serviço" ou conquistar uma profissão e constituir família. Para isso, veem a necessidade de morar fora da comunidade, em Teófilo Otoni ou em grandes centros (Belo Horizonte, Rio de Janeiro, Espírito Santo...), onde visualizam que "a vida sempre é mais fácil”, como expressou um jovem da comunidade São Julião.

Percebeu-se, ainda, que esses adolescentes e jovens têm a preocupação de, para além de constituir a própria família, oferecendo a ela condições dignas de vida, também ajudar sua família de origem (pai, mãe, irmãos e outros), com base no emprego que esperam conquistar.

Ao tratarem de seus projetos de vida e questionados acerca dos problemas sociais que mais os preocupam, os jovens da comunidade São Julião destacaram aqueles mais observados por eles, principalmente pela televisão ou de que ouviram falar: drogas, gravidez na adolescência, abuso sexual, roubo. Eles alegam que esses problemas não acontecem na comunidade ou que acontecem pouco, como drogas e roubos. Outra situação apontada como problema é a ausência de telefones públicos (orelhões) na comunidade e o meio visto como possibilidade de resolução desses problemas é a política.

Embora deem destaque à necessidade de intervenção política, nenhum deles tem uma relação de proximidade com ela, seja na comunidade, no âmbito da associação de moradores ou quilombola, seja na dimensão municipal, estadual ou federal, no sentido de se envolverem com os problemas sociais que perpassam essas esferas.

Para os adolescentes de Córrego Novo, drogas e alcoolismo são problemas preocupantes, preservar a natureza e o meio ambiente, formas de contribuir para 
99 SILVA. Projetos de vida de adolescentes e jovens de comunidades quilombolas do Vale do Mucuri um mundo melhor.

Um dos jovens beneficiados pelo Poupança

Em Cama Alta, adolescentes e jovens veem o isolamento (localização da comunidade, não acesso à internet e ao telefone público) como um significativo problema para a comunidade. No entanto, acreditam que nada está sendo feito para resolvê-lo, em particular no que diz respeito ao acesso à internet e ao telefone público. Quanto à localização da comunidade, a intenção não é transferi-la para outro lugar ou ir embora dela, mas torná-la conhecida pela sociedade envolvente. Segundo eles, isso já vem acontecendo, por exemplo, ao ouvirem menção à comunidade na rádio local, o que se tornou possível com o reconhecimento como quilombola e com o trabalho desenvolvido por essa equipe da UFVJM.

No tocante ao conhecimento acerca de seus direitos enquanto adolescentes e jovens, tal como postulados no Estatuto da Criança e do Adolescente e no Estatuto da Juventude, os jovens de Cama disseram ter tido contato com eles, mesmo que de forma breve, num curso de prevenção ao uso de drogas e à violência. Os jovens de São Julião também têm um vago conhecimento sobre eles, por meio da escola. Por outro lado, os adolescentes da Cama Alta e do Córrego Novo desconhecem esses direitos.

Quanto ao acesso aos programas sociais (estaduais ou federais) direcionados à juventude, apenas cinco jovens da comunidade Cama Alta participam do Poupança Jovem, política de inclusão social que visa diminuir a evasão escolar e aumentar a conclusão do ensino médio, bem como promover a formação cidadã, pessoal, educacional, cultural e profissional dos estudantes e, ainda, incentivar o protagonismo, a autonomia, a responsabilidade social e o cooperativis$\mathrm{mo}^{1}$

${ }^{1}$ Os alunos participantes do Programa recebem um benefício financeiro de $R \$ 1.000,00$ (mil reais) pela aprovação em cada série do ensino médio em que obtiver êxito. Eles devem participar ainda de atividades de aprendizagem complementar, atividades de caráter comunitário, cultural e esportivo, programas de acompanhamento social e outras atividades correlatas. Os participantes recebem a soma de $\mathrm{R} \$ 3.000,00$ (três mil reais), mais os rendimentos de poupança ao final do terceiro ano do ensino médio.

Jovem disse que, ao final do terceiro ano do ensino médio, momento em que terá acumulado os $\mathrm{R} \$$ $3.000,00$ reais oferecidos pelo programa, fará um curso com esse recurso.

Cabe ressaltar aqui a grande dificuldade de adolescentes e jovens das comunidades quilombolas de Teófilo Otoni em realizar cursos extraescolares, dada à necessidade de locomoção do campo para a cidade (Teófilo Otoni) e as despesas com transporte e alimentação.

Alguns jovens da Cama Alta também estão em contato com o Pronatec - Programa Nacional de Acesso ao Ensino Técnico e Emprego -, criado com o objetivo de ampliar a oferta de cursos de educação profissional e tecnológica ${ }^{2}$, o que não ocorre com os da Córrego Novo e da São Julião.

Constatamos que os adolescentes e os jovens dessas comunidades não têm, ou têm pouco, acesso às informações acerca dos programas destinados a eles, dos seus direitos, das possibilidades de inserção e permanência na universidade, sem contar o desconhecimento acerca da própria existência da universidade, nesse caso da UFVJM e dos cursos que ela oferece.

Os canais de informação (escola, universidade, poder público, dentre outros) não desempenham satisfatoriamente o papel de divulgação desses direitos, programas e possibilidades de qualificação (cursos técnicos e profissionalizantes), continuidade da escolarização (ensino superior) após o ensino médio, como, por exemplo, a necessidade de realizar o ENEM (Exame Nacional do Ensino Médio), se inscrever no SISU (Sistema de Seleção Unificada) ${ }^{3}$ e,

Foi criado para atender a estudantes do ensino médio público estadual que residem em municípios mineiros com alto índice de evasão escolar e vulnerabilidade social. www.poupancajovem. $\underline{\text { mg.br. }}$.

${ }^{2}$ www.pronatec.mec.gov.br.

${ }^{3}$ Sistema informatizado, gerenciado pelo Ministério da Educação (MEC), no qual instituições públicas de ensino superior oferecem vagas para candidatos participantes do Exame Nacional do Ensino Médio (Enem). www.sisu.mec.gov.br. 
100 SILVA. Projetos de vida de adolescentes e jovens de comunidades quilombolas do Vale do Mucuri no caso da UFVJM, também a possibilidade do SASI (Seleção Seriada) $)^{4}$.

Não identificamos a expressão de um protagonismo juvenil, com base no qual haja uma organização política desses jovens em sua comunidade, no sentido de tratar de assuntos e situações que dizem respeito à própria comunidade ou ao universo juvenil, tampouco para tratar de questões mais gerais. No entanto, percebemos que não estão totalmente alheios a esse contexto, uma vez que o trato de algumas situações se dá nos encontros informais e nos espaços de sociabilidade, bem como pode ser apreendido na expressão de suas opiniões, quando questionados.

\section{ConsideraÇÕES FinAis}

A história da educação do negro no Brasil é marcada, por um lado, pela interdição do acesso à educação formal, particularmente durante o período da escravidão até a década de 1950, quando se deu sua universalização. E, por outro lado, pela busca de oportunidades educacionais, tais como recentemente registradas na História da Educação, principalmente com os estudos realizados por pesquisadores negros. Há informações de que existiram experiências escolares vividas por ex-escravos ainda durante o sistema escravocrata, seja na educação escolar formal, por serem alguns deles "protegidos" de seus senhores, seja na educação informal, tal como a instrução religiosa oferecida por padres. No pós-abolição, no período que vai do final do século XIX até os anos 1960, a educação do negro, e pelo negro, foi promovida, sobretudo, pelas organizações políticas negras nas sociedades dançantes e clubes recreativos, nas associações beneficentes, na Frente Negra Brasileira, que

\footnotetext{
${ }^{4}$ Processo de Avaliação Seriada, que mede o conhecimento dos alunos ao término de cada série do Ensino Médio. A média dessas três notas resulta na classificação para inserção nos cursos oferecidos pela UFVJM. A ideia é estimular melhorias no Ensino Médio e favorecer os candidatos. www.ufvjm.edu.br/copese/ sasi.html
}

não se restringiu apenas à escolarização, mas também buscou a formação política de futuras lideranças e no Teatro Negro Brasileiro (TEN), dentre outros espaços negros.

No contexto do século XXI, as organizações negras e quilombolas ainda buscam oportunidades educacionais. Transformam suas demandas em políticas públicas educacionais, como forma de garantir a permanência do alunado negro e remanescente de quilombo na educação básica, bem como o acesso e permanência no ensino superior, tomando como base as diretrizes que norteiam, principalmente, a educação para as relações étnico-raciais (Parecer CNE 003/2004) e a educação escolar quilombola (Parecer CNE 16/2012).

Entre os jovens quilombolas das comunidades Cama Alta, Córrego Novo e São Julião participantes da pesquisa acerca dos projetos de vida, todos eles ainda cursando o ensino fundamental ou médio, atribui-se grande importância ao papel da educação escolar na conquista de uma profissão que venha a possibilitar melhores condições de vida para suas famílias (a dos pais ou parentes mais próximos e aquela que poderão constituir). Muitos deles desejam se tornar professores, veterinários ou engenheiros e, para isso, consideram que devem se dedicar aos estudos. O apoio da família também se mostra imprescindível para a efetivação desse desejo.

A educação escolar faz-se importante para a sociedade em geral, no entanto, a escolarização e a dedicação aos estudos sempre foram vistas como solução para o "problema do negro", uma via de ascensão social que possibilitaria a libertação de experiências com a discriminação racial e, sobretudo, "sair do lugar" socialmente atribuído ao negro (PEREIRA, 1987; BARBOSA,1978).

Embora desejem algumas das profissões que conferem status social, especialmente nos grandes centros urbanos, alguns jovens não veem como alcan- 
101 SILVA. Projetos de vida de adolescentes e jovens de comunidades quilombolas do Vale do Mucuri çá-las, e, por isso, almejam atividades que os mantenham no mundo rural, mas com certos privilégios, tais como as de vaqueiro ou fazendeiro.

Muitos deles expressam a vontade de, por meio dos estudos e do exercício da profissão escolhida, viver fora da comunidade. Nenhum considerou a possibilidade de exercer a profissão no interior da comunidade quilombola, como forma de aplicar os conhecimentos adquiridos em prol da própria comunidade.

Tal perspectiva foi apontada por uma das lideranças da São Julião, que, muito preocupada com o êxodo rural das gerações mais jovens, considera necessária a permanência, já que a luta travada para a demarcação do território quilombola tem como um dos seus propósitos garantir um pedaço de terra a essas gerações, no lugar onde é construída toda a lógica de vida que faz da São Julião uma comunidade.

Parte da população jovem que compõe as três comunidades remanescentes de quilombos de Teófilo Otoni está motivada a migrar para os grandes centros urbanos, tais como Belo Horizonte, Rio de Janeiro, São Paulo e Espírito Santo, para trabalhar em atividades residuais da economia ou nas safras de produtos sazonais.

Mesmo entre os jovens da pesquisa, ainda em fase de escolarização, encontramos aqueles que se ausentam da escola por um período de aproximadamente três meses para trabalhar na colheita de café, no Espírito Santo.

No caso daqueles que permanecem nas comunidades, a maioria se dedica às atividades rurais locais, especialmente nas terras do entorno, e aos trabalhos de capinagem, à retirada do leite das vacas, dentre outras, recebendo uma pequena quantia por serviço prestado.

Se, por um lado, a educação escolar é tida pelos jovens como meio de melhores condições de vida, com o exercício de uma profissão, e de saída da comunidade, por outro lado, ela também se mostra um obstáculo à concretização de seus projetos de vida. Essa contradição é percebida na descrição acerca da falta de estrutura das escolas frequentadas por eles e de recursos humanos.

Por se tratarem de escolas rurais, muitas delas não apresentam condições adequadas de funcionamento (salas de aula, laboratórios de informática, bibliotecas, etc.), tampouco professores para todas as disciplinas da grade curricular. Com isso, verifica-se um comprometimento da qualidade do ensino.

Apesar da importância atribuída à escola e aos estudos, alguns jovens expressaram sua desmotivação frente a conteúdos que se mostram difíceis, especialmente aqueles referentes às disciplinas de Português e Matemática, e/ou sem sentido, por não estarem associados a suas experiências e cotidianidade.

Esses jovens parecem não ter clareza acerca da possibilidade de uma educação escolar quilombola (Parecer CNE/CEB 16/2012) que articule saberes considerados universais e saberes que dão ênfase à identidade étnico-racial, à história e cultura da África e afro-brasileira (Lei 10639/2003) e às questões que envolvem território e territorialidade, próprios da condição de negro, rural e quilombola.

Uma remota percepção aparece no desejo de uma das lideranças da comunidade São Julião, muito envolvida com a educação oferecida pela escola existente na comunidade, do $1^{\circ}$. ao $5^{\circ}$. ano, e angustiada com aquela ofertada fora dela, nas escolas do entorno que atendem aos jovens do $6^{\circ}$ ao $9^{\circ}$. ano do ensino fundamental e aos que frequentam o ensino médio.

Para ela, a comunidade deveria ser um grande "internato" rural, com educação profissionalizante e aplicada na própria comunidade, com conteúdos que fizessem sentido e tivessem significado para os jovens, e articulação com a história de origem e cultura afro-brasileira da comunidade. Embora não conhece- 
102 SILVA. Projetos de vida de adolescentes e jovens de comunidades quilombolas do Vale do Mucuri dora das Diretrizes Curriculares para a Educação Escolar Quilombola, seu desejo vai ao encontro de suas proposições.

REFERÊNCIAS BIBLIOGRÁFICAS

jovens e adultos no Brasil. Educação \& Sociedade, Campinas, vol. 26, n. 92, p.1115-1139, out./2005.

HADDAD, Sérgio; DI PIERRO, Maria Clara. Aprendizagem de jovens e adultos: avaliação da década da educação para todos. São Paulo em Perspectiva, 14 (1), 2000 .

HALBWACHS, Maurice. A memória coletiva. São Paulo: Vértice/ Revista dos Tribunais, 1990.

ANJOS, Rafael Sanzio Araújo dos. Cartografia e Cultura: Territórios dos remanescentes de quilombos no Brasil. VIII Congresso Luso-Afro-Brasileiro de Ciências Sociais. Coimbra, 16 a 18 de setembro de 2004.

ARRUTI, José M. A. A emergência dos "remanescentes": notas para um diálogo entre indígenas e quilombolas. Caxambu, Anpocs, 1997. (mimeo).

.O quilombo conceitual: para uma sociologia do artigo 68 do ADCT. In: Texto para discussão: Projeto Egbé - Territórios negros (KOINONIA), 2003.

BRASIL. Constituição da República Federativa do Brasil. Brasília: Senado, 1988.

. Diretrizes curriculares nacionais para a educação das relações Etnicorraciais e para o ensino da história afro-brasileira e africana. Brasília/DF: SECAD/ME, 2004.

. Parecer CNE/CEB no 16/2012. Diretrizes Curriculares Nacionais para a Educação Quilombola. Disponível em: http://etnicoracial.mec.gov.br/images/pdf/diretrizes_curric_educ_quilombola.pdf.

BOLETIM INFORMATIVO DO NUER. Legislação sobre Quilombos. Vol.02, n 2, 2005.

CEDEFES. Comunidades quilombolas de Minas Gerais no século XXI: história e resistência. Belo Horizonte: Autêntica, 2008.

CHAGAS, Miriam de Fátima. A política do reconhecimento dos "remanescentes das comunidades dos quilombos". Horizontes Antropológicos, Porto Alegre, ano 7, n. 15, p. 209-235, jul. 2001.

COMISSÃO PRÓ-ÍNDIO DE SÃO PAULO. O caminho da titulação. Disponível em: <http://www.cpisp. org.br/terras/html/comosetitula_caminho.asp $>$ Acesso em: 10 ago. 2010.

DI PIERRO, Maria Clara. Notas sobre a redefinição da identidade e das políticas públicas de educação de

KRAMER, Sonia. As crianças de 0 a 6 anos nas políticas educacionais no Brasil: a educação infantil e/é fundamental. Educação \& Sociedade. Campinas, vol. 27, n. 96 (Especial), p.797-818, out. 2006.

LEITE, Ilka B. Os quilombos no Brasil: questões conceituais e normativas. Disponível em: http://www. nead.org.br/index.php?acao=artigo\&id=21.

LIMA, Deborah. Firmados na terra: a produção do significado de território em dois quilombos de Minas Gerais. $32^{\circ}$. Encontro Anual da ANPOCS. Caxambu/ MG, 2008.

MARQUES, Carlos Eduardo. De quilombos a quilombolas: notas sobre um processo histórico-etnográfico. 05/05/2010. Disponível em http://www.cedefes.org.br/index.php?p=afro_detalhe\&id_afro $=2224$ acesso em 11 de agosto de 2010.

O'DWYER, E. C. Introdução. In: O'DWYER, E. C. (Org.). Quilombos: identidade étnica e territorialidade. Rio de Janeiro: FGV, 2002.

QUEIROZ, Maria Isaura. Relatos orais: do "indizível" ao "dizível". In: SIMSON, Olga de Moraes von (Org.). Experimentos com histórias de vida: Itália-Brasil. São Paulo: Vértice/Revista dos Tribunais, 1988.

RATTS, Alecsandro J. P. A voz que vem do interior: intelectualidade negra e quilombo. In: BARBOSA, Lucia $\mathrm{M}^{\mathrm{a}}$ de Assunção et alii (Orgs.). De preto a afro-descendente: trajetos de pesquisa sobre o negro. São Paulo: Edufscar, 2004.

. (Re)conhecer quilombos no território brasileiro: estudos e mobilizações. In: Fonseca, Maria Nazareth Soares (Org). Brasil afro-brasileiro. $2^{\circ}$ ed. Belo Horizonte: Autêntica, 2006.

SILVA, Eva Aparecida et alii. Comunidades remanescentes de quilombo do Vale do Mucuri: conhecer para transformar. Relatório técnico. Belo Horizonte: 
103 SILVA. Projetos de vida de adolescentes e jovens de comunidades quilombolas do Vale do Mucuri FAPEMIG, 2010.

. Jovens quilombolas e seus projetos de vida.

Relatório técnico. Belo Horizonte: FAPEMIG, 2014. 